\title{
Familiares, profissionais de saúde mental e a alteridade da loucura*
}

\section{Relatives, mental health professionals and otherness of madness}

\author{
Teresinha Cid Constantinidis ${ }^{1}$, Ângela Nobre de Andrade ${ }^{2}$
}

http://dx.doi.org/10.11606/issn.2238-6149.v26i3p355-363

\begin{abstract}
Constantinidis TC, Andrade AN. Familiares, profissionais de saúde mental e a alteridade da loucura. Rev Ter Ocup Univ São Paulo. 2015 set.-dez.;26(3):355-63.
\end{abstract}

RESUMO: Este estudo pretende compreender a relação de familiares e profissionais de saúde mental com a loucura e discutir suas possíveis repercussões nas ações de atenção e cuidado à pessoa com sofrimento psíquico. Em perspectiva qualitativa de investigação, foram entrevistados familiares de usuários e profissionais de dois centros de atenção psicossocial. A análise temática do conteúdo indicou regularidades discursivas que delinearam quatro categorias: (1) termos e ideias associadas à loucura; (2) loucura concebida como falta; (3) comportamento diferente e o diagnóstico; (4) loucura, doença mental e controle. Os resultados apontam que, na visão dos profissionais, a loucura está aquém em relação a um modelo de saúde mental idealizado. Diante disso, buscam classificar e controlar suas manifestações. Os familiares não acreditam na utilização de possibilidades e meios relacionais com seu familiar com sofrimento psíquico, associando-o à invalidez e tentam controlá-lo, como forma de lidarem com a alteridade.

DESCRITORES: Transtornos mentais; Relações familiares; Pessoal de saúde; Serviços de saúde mental.
Constantinidis TC, Andrade AN. Relatives, mental health professionals and otherness of madness. Rev Ter Ocup Univ São Paulo. 2015 Sept.-Dec.;26(3):355-63.

ABSTRACT: This study aims to understand the relationship of family and mental health professionals with the otherness of madness and discuss its potential impact on the actions of attention and care to people with psychological distress. In qualitative research perspective, family members from two centers for psychosocial care and mental health professionals from these institutions were interviewed. A thematic content analysis indicated discursive regularities that delineated four categories: (1) terms and ideas associated with madness; (2) madness conceived as missing; (3) different behavior and diagnosis; (4) madness, mental illness and control. The results show that, in the professional vision, madness falls short in relation to an idealized mental health model. Therefore, they seek to classify and control its manifestations. Family members do not believe in possibilities and means to your family with psychological distress, associating it with the disability and try to control it as a way to deal with otherness.

KEYWORDS: Mental disorders; Family relations; Health personnel; Mental health services.

\footnotetext{
*O presente estudo faz parte dos resultados da tese de doutorado "Familiares de pessoas com sofrimento psíquico e profissionais de saúde mental: encontros e desencontros", Programa de Programa de Pós-Graduação em Psicologia da UFES.

1. Universidade Federal do Espírito Santo (UFES), Curso de Terapia Ocupacional, Departamento de Terapia Ocupacional.

2. Universidade Federal do Espírito Santo (UFES), Programa de Pós-Graduação em Psicologia.

Endereço para correspondência: Teresinha Cid Constantinidis. Departamento de Terapia Ocupacional da UFES. Rua Marechal Campos s/n. Maruipe. Vitória, ES. CEP: 29055-000. e-mail: teracide@gmail.com
} 


\section{INTRODUÇÃO}

$\mathbf{O}$ processo de desinstitucionalização busca novas formas de compreensão da loucura, que passa a ser percebida como construção social mais ampla. Busca desconstruir a lógica manicomial concreta e simbólica que atravessa também as relações sociais e culturais com a loucura.

Espera-se que a família ocupe o lugar significativo de protagonista no processo de inclusão da loucura. Além da participação do tratamento, a família poderá vir a ser um agente de transformação da cultura e lógica manicomial, trazendo a diferença como possibilidade e enriquecimento das relações entre os sujeitos ${ }^{1}$.

Da mesma forma, a responsabilização por manter a pessoa com sofrimento psíquico em comunidade, construindo uma autonomia e cidadania possíveis a ela, evitando a internação, não é só do familiar, mas também do profissional de saúde mental. Inserido no contexto da política de assistência em saúde mental, o profissional deve fazer a sua parte para o reconhecimento da diferença que a loucura representa e de possibilidades de convivência sem ter que excluí-la.

Neste estudo adotamos termos como loucura e sofrimento psíquico de acordo com o contexto em que foram utilizados. O termo loucura é extremamente polissêmico, com diversos sentidos históricos, com uma enorme diversidade de conteúdos e formas de experiências e percepções ${ }^{2}$. Será utilizado quando nos referirmos à experiência de ruptura com o sentido comum de experiência compartilhada pelo grupo social. Já o termo sofrimento psíquico é uma das formas de designação da loucura, quando apreendida como objeto de estudo e intervenção pelas ciências da saúde, mais especificamente pela saúde mental. Traduz indicadores para além da doença mental e da sintomatologia, tal como tratada pela psiquiatria. Volta-se para o sujeito em sofrimento resultante de sua diferença de ser e de estar no mundo e do desequilíbrio entre suas as capacidades internas e as exigências do contexto social. A adoção deste termo está em consonância com as discussões realizadas na III Conferência Nacional de Saúde $\mathrm{Mental}^{3}$, realizada em 2001, sobre a adoção deste termo em substituição a denominação de "doença mental", que remete à rotulagem, à inexpressão do ser humano e à sua exclusão social como forma de tratamento.

Salientamos a importância dos termos utilizados, pois os termos refletem discursos presentes em determinada cultura e, ao mesmo tempo, discursos controlam os termos utilizados. A produção discursiva relaciona-se com uma dada época e constitui a maneira de ver o mundo de uma dada formação social ${ }^{4}$.

$\operatorname{Vechi}^{5}$ (p.489) propõe três tendências discursivas que marcaram o processo pelo qual a loucura se tornou e se mantém como objeto do discurso científico no Brasil: a manicomial, a de saúde mental e a de desinstitucionalização. No discurso manicomial a loucura é reduzida a estruturas, a síndromes e a diagnósticos, baseados em aspectos como incompreensibilidade, periculosidade e incapacidade, que justificaria a internação. No discurso da saúde mental, o foco prioritário do tratamento seria a produção de saúde mental pela adaptação social e não apenas pela modificação da patologia, como no discurso manicomial. No entanto, a noção de doença mental permanece neste discurso, ainda que numa compreensão ampliada, definida numa perspectiva biopsicossocial.

Diferentemente dos demais, o discurso da desinstitucionalização propõe a busca de novas formas de compreensão da loucura, sem restringi-la à ordem da patologia, passando a ser percebida como uma construção social mais ampla. Esse discurso indica a necessidade de uma desconstrução da noção de doença, que justificaria os procedimentos assistenciais que podem levar à exclusão social da pessoa reconhecida como louca. Para Rotelli et al. ${ }^{6}$ (p.48), não se trata de negar a dor, o mal-estar, que podem ser provocados pela diversidade da experiência, mas de recusar a redução ao conceito de doença, a compreensão da complexidade do fenômeno loucura/sofrimento psíquico.

\section{Alteridade e loucura}

A loucura e o louco despertam uma série de respostas nas pessoas de seu meio social. A exclusão e a lógica manicomial estão presentes não apenas nos dispositivos psiquiátricos, mas também nas relações sociais com a loucura. As ideias de convívio com a diferença e da cidadania, tão defendidas dentro da proposta de desconstrução do modelo manicomial, estão associadas ao reconhecimento e ao respeito pelo outro.

Analisando esse "outro" pela via do campo da subjetividade, Rolnik ${ }^{7}$ (p.152) toma alguns conceitos da física como base - caos e equilíbrio - e desenvolve a ideia do outro nos planos visível e invisível. No plano visível da alteridade, o outro seria tudo aquilo exterior a um eu, que se apreende pela percepção. Partindo do princípio de que a realidade não se constitui apenas pelo visível, a autora analisa o outro também na dimensão invisível.

A dimensão invisível nos arranca permanentemente de nós mesmos, na medida em que rompe o nosso equilíbrio e nossos contornos identitários. O contato com a produção de diferença nos levaria a essa dimensão do invisível, que 
nos desestabiliza e nos coloca a exigência de criarmos um novo corpo, uma nova forma de sentir, de pensar e de agir. Desse ponto de vista do invisível, a alteridade é o próprio caos e a tendência é viver um mundo sem alteridade, no equilíbrio, mantendo os corpos na sua atual configuração, cada um ocupando um lugar e uma função no todo.

O pensamento modelar ocidental tende a negar a alteridade, na tentativa de fixar um suposto equilíbrio. Tendemos a nos fechar ao mundo exterior a fim de manter a estabilidade, a ordem. A ordem e a desordem não se contrapõem, colaboram para nossa organização, são inerentes à vida. A ordem contém a desordem, sendo que a imanência da ordem, o caos ${ }^{8}$. No entanto, resistimos ao que nos é estranho, ao que supostamente ameaça nossa identidade.

Pensar a loucura como uma possibilidade é deixar de pensar essa alteridade como fonte de destruição, deixando de ser ameaça.

\section{Familiares, profissionais de saúde mental e a loucura}

Focando na relação da pessoa com transtorno mental e seus familiares, podemos destacar a dificuldade de conviver com a produção de diferença que se instala nessa relação $0^{9,10}$. A presença de um membro com transtorno mental na família pode trazer comprometimentos em diversos níveis relacionais que resultam em abalos que demandam a criação de novos territórios existenciais ${ }^{11,12}$. O termo território existencial pode ser definido como o espaço, o campo de experiência que dá sentido à existência em um dado momento. Ele é composto por projetos e representações que resultarão em uma série de comportamentos, de investimentos nos tempos e nos espaços sociais, culturais, estéticos, cognitivos ${ }^{13}$.

Os familiares inicialmente tendem a atenuar o "comportamento diferente" no sentido de suportar e relativizar a sua gravidade. Na medida em que essa convivência vai se tornando insustentável, marcada pelo desconforto da imprevisibilidade, tendem a identificar o que é diferente, estranho e incomoda e buscar entendimento por meio da doença ${ }^{14}$. Assim, na criação de um novo território existencial, esses familiares tentam normalizar o estranho, passam a classificar os comportamentos desviantes, encerrando essa realidade em um sistema coerente.

Moraski e Hildebrandt ${ }^{15}$ (p.199) destacam que as elaborações constituídas pelos familiares sobre sofrimento psíquico de seu ente são apropriações do conhecimento adquirido na sociedade e pelo contato com os serviços médicos. Os comportamentos diferentes do louco passam a ser relacionados à doença mental.
Estudo realizado por Maciel et al. ${ }^{16}$ (p.199) aponta que o fato da pessoa ser doente mental faz a diferença para os familiares, já que a doença mental é considerada como diferente das demais, pois acomete alguém que não está apenas doente, mas que é doente, caracterizando uma incurabilidade.

A doença mental apresenta-se como uma doença particular dentro da medicina. Para Gadamer ${ }^{17}$ (p.172), na psiquiatria a própria compreensão da doença é doente. Diferente de outras diagnoses médicas, a categoria de doença para a psiquiatria não é uma realidade evidente no mesmo sentido que em outras especialidades. Para o autor, "a sinistra escuridão presente na enfermidade mental não perde, absolutamente, sua incompreensibilidade, ainda que estejam à disposição do médico possibilidades de domínio da doença através de, por exemplo, psicofármacos" ${ }^{17}$ (p.172).

Andrade $^{18}$ (p.5) aponta que o arcabouço teórico da psicologia e de outras profissões que se ocupam da saúde mental visa não somente explicar/compreender as faltas e sofrimentos humanos, como 'consertá-los' no reencontro com um suposto equilíbrio natural.

Existem modelos morais universais que participam ativamente para imposição de modelos ideais, valores e comportamentos. Essas interações e intervenções baseadas em valores morais põem em prática a negação da diferença; estabelecem-se de forma verticalizada, concebendo o outro pela falta de algum atributo esperado dentro do modelo de referência.

O profissional de saúde mental diante de pessoa com sofrimento psíquico pode ver apenas desorganização e desestruturação por se tratar de uma realidade diferente de supostos modelos. Diante de uma demanda diferente da verdade internalizada por esse profissional, ele pode reagir despotencializando o outro ${ }^{18}$.

\section{A desinstitucionalização, os familiares e os profissionais de saúde mental}

Com o advento da psiquiatria, no século XVIII com Pinel na França e Tuke na Inglaterra, a loucura passa a ser objeto da medicina e ser considerada doença mental. Na perspectiva dos psiquiatras da época, para tratar era preciso excluir. O chamado doente mental, isolado no hospital psiquiátrico, era submetido a um modelo de tratamento idealizado por Pinel, o tratamento moral. Segundo este modelo, era necessário isolar o doente mental em um meio que pudesse fazê-lo retornar a uma vida mais "natural", dentro das regras e normas que o permitissem conviver socialmente. 
A partir da Segunda Guerra Mundial os hospitais psiquiátricos e a forma de tratar o louco começam a ser questionados, quando denúncias ao modelo de exclusão tornam-se proeminentes e culminam em debates que evoluem para os movimentos de transformação dessas instituições. Nesse contexto, surgem movimentos que buscam romper a relação cuidado-exclusão, propondo a abertura e transformação das instituições psiquiátricas como os movimentos da Psiquiatria comunitária, na Inglaterra, e Psicoterapia Institucional na França ou a superação destas mesmas instituições, como a Psiquiatria Democrática italiana. A despeito das divergências, esses movimentos têm em comum o repúdio à ordem psiquiátrica tradicional e a proposição de novas abordagens (clínicas, institucionais e sociais) para o sofrimento psíquico.

No Brasil, os primeiro sinais de possibilidade de transformação da assistência psiquiátrica ocorreram na década de 1980, quando se iniciou o movimento que se convencionou chamar de "Reforma Psiquiátrica Brasileira", que culminou com a "Lei da Reforma Psiquiátrica" sancionada em 2001. Como principais desdobramentos dessa lei houve a redução de leitos em hospitais psiquiátricos, a criação de leitos psiquiátricos em hospitais gerais e a criação de serviços locais extra-hospitalares, substitutivos ao modelo manicomial, tais como serviços de atenção psicossocial (CAPS, NAPS, Hospitais-dia, Residências Terapêuticas), além da modificação do arcabouço jurídico legal que legitima a internação psiquiátrica e o estatuto de periculosidade e incapacidade. De maneira geral, esses novos serviços se caracterizam pela utilização intensiva de um conjunto amplo e complexo de tecnologias terapêuticas e práticas psicossociais dirigidas a manter a pessoa com transtorno mental junto à sua família e à comunidade ${ }^{19}$.

Essas transformações, certamente, têm resultado em uma implicação maior da família. O tempo de convivência com a pessoa com sofrimento psíquico é maior, já que ela não vive mais no hospital psiquiátrico. $\mathrm{O}$ manicômio, com sua tendência de totalizar a vida dos internos, havia excluído essa convivência e o compartilhamento de vivências entre esses familiares.

São os familiares que geralmente identificam algum problema, buscam o tratamento, tornam-se responsáveis pela administração das prescrições médicas, e devem enfrentar e manejar os momentos de crise, de agravamento do quadro sintomatológico. Em face dessa demanda de cuidados, os familiares têm que redimensionar as expectativas quanto ao futuro de seu familiar com sofrimento psíquico e quanto ao próprio futuro.

A afirmação da cidadania da pessoa com sofrimento psíquico, promover ou seu retorno ou sua permanência no território, (re)aproximá-lo da família, são tarefas dos serviços de assistência em saúde mental, que estão afinadas com a Reforma psiquiátrica e a busca de superação do modelo manicomial. No entanto, muitas práticas se limitam à eliminação dos sintomas e encontra-se serviços de assistência em saúde mental que visam apenas a manutenção da ordem.

$\mathrm{Na}$ banalização de suas ações, sem que os profissionais questionem os pressupostos ideológicos que as embasam, as práticas manicomiais são naturalizadas no dia a dia institucional. Os CAPS, as residências terapêuticas, enfim, as modalidades terapêuticas propostas pela política de saúde mental, afinada com o ideal da chamada Reforma Psiquiátrica Brasileira, não garantem por si só a superação do manicômio.

O aparato manicomial, é preciso insistir, não é o hospital psiquiátrico, embora seja a mais expressiva instituição na qual se exercita o isolamento: é o conjunto de gestos, olhares atitudes que fundam limites, intolerâncias e diferenças, em grande parte informadas pelo saber psiquiátrico, existentes de forma radicalizada no hospício, mas presentes também em outras modalidades assistenciais e no cotidiano das relações sociais ${ }^{20}(\mathrm{p} .141)$.

É importante ressaltar que o processo de desinstitucionalização implica a necessidade de reflexão por parte dos profissionais, sobre sua prática cotidiana de assistência à pessoa que passa pela experiência da loucura. É necessário que os profissionais de saúde mental não percam de vista os "desejos de manicômios" que atravessam o tecido social, ou seja, o desejo de exclusão e de exploração que impedem as mudanças na relação com a loucura. "As equipes inseridas nos serviços de saúde mental podem, sem dar-se conta, reproduzir a institucionalização e, portanto, afirmar o manicômio....”21 (p.312).

Diante do exposto, este estudo pretende compreender a relação de familiares e profissionais de saúde mental com a loucura e discutir suas possíveis repercussões nas ações de atenção e cuidado à pessoa com sofrimento psíquico.

\section{PERCURSO METODOLÓGICO}

O interesse pelo universo dos significados, dos motivos, das crenças, dos valores, das atitudes, além de se ocupar com o nível da realidade não visível, que precisa ser exposta e interpretada, base deste trabalho, são características da pesquisa qualitativa ${ }^{22}$ e proposta deste estudo. 
A pesquisa de campo foi realizada entre março e outubro de 2010. Os participantes escolhidos foram profissionais de saúde mental e familiares de pessoas com sofrimento psíquico, pois estes atores estão envolvidos diretamente nos objetivos da pesquisa. O estudo foi realizado em Centro de Atenção Psicossocial (CAPS), pois se trata de um serviço de saúde aberto, comunitário que oferece atendimento diário às pessoas com transtornos mentais severos e persistentes, que busca manter uma rede de apoio territorial e as ações voltadas aos familiares ocupam lugar de destaque, facilitando acesso a esses atores.

Foram selecionadas para campo da pesquisa dois CAPS de uma cidade da região sudeste do país, os únicos da cidade na época da realização da pesquisa.

O projeto da pesquisa foi aprovado pelo Comitê de Ética em Pesquisa do Centro de Ciências da Saúde da Universidade Federal do Espírito Santo - UFES, em 12 de novembro de 2009, registrado sob $\mathrm{n}^{\circ} 149 / 09$. O projeto foi também avaliado e aprovado pelo comitê cientifico da Secretaria de Saúde do município, que aprovou e facilitou $o$ acesso as instituições referidas.

Foi feito contato com os coordenadores dos CAPS, que forneceram informações sobre a rotina institucional e auxiliaram nas estratégias de seleção de familiares e profissionais para as entrevistas. A proposta foi entrevistar uma pessoa de cada família, não importando o sexo, idade, profissão ou grau de escolaridade. O critério de inclusão foi familiares que mantinham convivência cotidiana com o familiar com sofrimento psíquico, contato com os serviços de saúde mental e com seus profissionais. Em relação aos profissionais, o critério de inclusão foi trabalhar em um dos CAPS citados, atender diretamente as pessoas com sofrimento psíquico e ter disponibilidade e concordância em participar da entrevista, não importando a especialidade do profissional.

Foram entrevistados nove familiares, em suas residências ou no CAPS - conforme preferência do familiar - que tinham grau variado de parentesco com a pessoa com sofrimento psíquico. Em relação aos profissionais, foram entrevistados doze profissionais: dois assistentes sociais, um médico, cinco psicólogos, um terapeuta ocupacional, um musicoterapeuta, um arteterapeuta e um enfermeiro.

Para delimitação do número de participantes, foi adotada a amostragem por saturação. Este critério consiste na definição do número de participantes no decorrer do processo de coleta de dados, isto é, quando a amostra dava condições de aperfeiçoamento e reflexão teórica proposta e as informações passaram a se repetir, as entrevistas foram encerradas ${ }^{23}$.

A técnica de coleta de dados foi a entrevista semi- estruturada ou semi-dirigida de questões abertas ${ }^{21}$. Os tópicos abordados com os familiares e profissionais e que dizem respeito a este trabalho, referiram-se, de forma geral, à sua visão de loucura/sofrimento psíquico, dos limites e possibilidades no cotidiano de atenção e cuidado dispensado aas pessoas em sofrimento psíquico dos encargos familiares.

As entrevistas, que duraram em media 40 minutos, foram gravadas e posteriormente transcritas.

O tratamento do material, a sua codificação, deu-se por intermédio da análise de conteúdo, na modalidade de análise temática que "procura nas expressões verbais ou textuais os temas gerais recorrentes que fazem a sua aparição no interior de vários conteúdos mais concretos" ${ }^{\$ 23}$ (p.442). Tendo em vista que este estudo não pressupõe uma análise quantitativa, as categorias foram sendo delineadas não necessariamente pela repetição de falas, mas também pela relevância dos relatos no encaminhamento das discussões ${ }^{21}$.

\section{RESULTADOS E DISCUSSÃO}

Os resultados apontaram regularidades discursivas que delinearam quatro categorias: (1) Os termos, as idéias associadas à loucura; (2) A loucura concebida como falta; (3) O comportamento diferente e o diagnóstico; (4) Loucura, doença mental e controle. No final de cada trecho de relato, a letra $\mathrm{P}$ indica que o relato foi feito por profissional e a letra $\mathrm{F}$ por familiar. Os números correspondem à identificação numérica de cada participante, por exemplo, F2 indica que o relato foi feito pelo familiar número dois.

\section{Os termos, as ideias associadas à loucura}

Os inúmeros termos relacionados à loucura compõem diferentes discursos e, para alguns profissionais, assim como houve mudanças do discurso e da relação social com o fenômeno da loucura no decorrer dos tempos, assim também os termos utilizados sofreram mudanças.

Eu uso transtorno mental, não uso o termo portador, né? Uso pessoas com transtorno mental porque o termo em si traz um marco, uma ênfase muito da doença, como se o sujeito se perdesse nessa relação com a doença (P1).

Pelo fato de eu estar muito tempo militando nesta causa da reforma psiquiátrica, a própria reforma mesmo, os termos mudam: doença para transtorno mental severo, persistente, às vezes uma coisa mais branda, sofrimento psíquico grave, mas assim o termo mais corrente, que consta em portaria, é transtorno mental grave e a gente coloca este adjetivo, este aposto característico das psicoses. Até para marcar com relação a outras patologias (P8). 
Nesses dois recortes, a forma de utilização dos termos ilustra diferentes discursos vigentes na abordagem do fenômeno da loucura. Foi possível perceber que enquanto P1 utiliza um discurso que se aproxima ao discurso da desinstitucionalização ${ }^{5}, \mathrm{P} 8$, se afasta desse discurso que seria referencial da chamada reforma psiquiátrica brasileira, da qual ele se identifica como militante. Na forma como é utilizada pelo profissional, termos como transtorno mental substitui o termo doença mental, mas ainda favorece a "patologização" da clientela atendida, ao associá-lo a diagnósticos.

Outros profissionais, ainda, desconsideram os termos relacionados como reflexo de uma determinada concepção teórica e de posicionamento político e técnico diante da questão da loucura.

Eu uso, depende do contexto, normalmente... Quando eu vou escrever, eu procuro escrever sobre adoecimento psíquico. Às vezes quando você tá conversando com pessoas leigas, pessoas que falam de loucura, pra explicar o que é isso e pra entendimento melhor, você fala doença mental (P3).

É importante notar que os relatos apresentados são de profissionais que atuam em serviços de saúde mental, em CAPS, considerados dispositivos estratégicos da reforma dos cuidados em saúde mental no Brasil, que busca uma ruptura paradigmática em relação ao modelo anterior, que fundou a noção de doença mental.

\section{A loucura concebida como falta}

Olha só, transtorno mental pra mim é um prejuízo... É uma doença que está prejudicando a pessoa nas relações familiares dela, no convívio em geral, né? É uma pessoa que não... que em função desta patologia, ela não dá conta ... (P5).

São transtornos de origem mental que atrapalham o sujeito na sua vida cotidiana, que vão atrapalhar o cotidiano, as relações familiares, as atividades do seu dia a dia, o trabalho, o auto-cuidado (P4).

Eu acho que quando a gente fala sofrimento psíquico, o próprio nome diz mesmo, de um sofrimento mesmo, algo de um desajuste assim, algo que aconteceu em uma etapa $d a$ vida e transformou a vida desse sujeito (P2).

Os discursos desses profissionais são marcados por palavras como prejuízo, atrapalhar, desajuste (grifadas nos relatos). Apontam que esses profissionais colocam o sofrimento psíquico em posição de desvantagem em relação a um modelo de saúde mental em que a pessoa tem que ter boas relações familiares e com seu entorno, habilidades na condução de suas atividades cotidianas, ajuste de seu sofrimento de forma que este não modifique sua vida. Seria aberta uma valoração do que deve ser a vida e o modo de existência, uma valoração moral que refletiria na relação que se estabelece entre esses profissionais, usuários e familiares.

Caso seja assumida a conotação de falta à loucura/ sofrimento psíquico, reduzindo-a a esta única dimensão, perde-se a possibilidade de abrir espaço para um encontro com o louco, que acaba sendo desvalorizado, desautorizado e enquadrado já que suas manifestações são classificadas, controladas, na tentativa de consertá-las.

\section{O comportamento diferente e o diagnóstico}

Alguns familiares significam o comportamento diferente observado no cotidiano familiar com a pessoa com sofrimento psíquico a partir da ampliação do contato desta pessoa com o meio social, como ingresso na escola, que aponta essa diferença como doença.

Na verdade, a gente não notou que ele tinha qualquer coisa diferente, tudo que ele fazia a gente achava que era coisa de criança, de criança assim, porquinha, né? A gente achava que era coisa comum e foi indo, foi indo... e a escola que me cobrava isso aí, que tinha que levar para psicólogo, pra neurologista. Ai eu comecei a correr atrás, a levar para o neurologista (F3).

Inicia-se aí, o processo de demarcação de fronteiras, o que fica dentro dos padrões, como normal e o que fica fora deste, como pessoa que precisa de tratamento. Os resultados apontam que a diferença, que até então fazia parte do convívio familiar, passa a ser doença que precisa ser tratada e a criança, no caso, passa a ser alvo de atenções especiais, tanto na família como na escola, com grandes chances de ser excluída do grupo de crianças típicas.

Outras vezes a diferença, o comportamento dito diferente, é aceito pelos familiares, faz parte do cotidiano familiar, até que algo se intensifica, desestabilizando esse convívio. É a partir da chamada crise, que se instaura a necessidade de tratamento:

Desde que a gente foi morar junto, ela tinha assim..., ela se sentia muito alegre, ela chorava e quando se sentia muito triste, ela sorria, mas pra mim aquilo não era nada de mais. Era normal, dela ficar alegre chorar, ficar triste, sorrir, este é o jeito dela mesmo. (...). E ai passado oito ou nove anos, ela deu a primeira crise. Ela começou a ficar nervosa dentro de casa, começou a quebrar as coisas e aí foi se repetindo. Aí comecei a levar no médico... (F2). 
Na busca pelo tratamento, pelo controle da situação, surge também, por parte da família, a busca de explicação daquilo que está causando, na maioria das vezes, sofrimento ao familiar que está trazendo turbulência ao cotidiano dessas pessoas. Os resultados indicam a necessidade do familiar de compreender essa vivência que vem formulada pelo pedido de um diagnóstico.

Aquilo tava me consumindo e eu queria descobrir porque o B. é daquele jeito. O diagnóstico me ajudou porque até então: poxa, cadê meu tempo, o que eu tô fazendo, tô correndo atrás e ninguém te fala o que é (F8).

$\mathrm{O}$ enquadre do comportamento diferente em um diagnóstico, parece ser um norteador para o familiar, que até, então, sentia-se à deriva com suas experiências e alienado quanto às suas ações. $\mathrm{O}$ familiar só conhece a loucura pelo efeito que ela causa nele.

O diagnóstico psicopatológico é um lugar que a loucura passa a ocupar, podendo ser referida com um nome. Deixa a categoria de inominável para a concretude de um código a ser compartilhado, dando garantia de doença à loucura ${ }^{15}$. Assim, o diagnóstico não é só necessidade de profissionais, que muitas vezes se furtam da tarefa de conversar sobre o tema com a família, mas também de familiares:

Me angustiava muito, porque ninguém chegava e falava: A. tem isso assim, assim. (...) Agora eu sei. Então ele fazia o tratamento aqui, mas eles não falam, os profissionais não querem falar o que a pessoa tem (F3).

$\mathrm{Na}$ tentativa de responder a essas questões, alguns profissionais parecem evasivos aos familiares que não se sentem satisfeitos com as respostas.

Olha, eu investiguei junto com o médico. O médico ficou muito, achei assim..., muito evasiva a explicação que ele me deu: é como um eixo de um carro que está funcionando neste sentido e por causa de um choque, um esbarrão qualquer, ele trabalha ao contrário. Achei válido, mas poderia ser uma coisa mais..., o médico não te diz qual é o problema. Acho que eles não têm a resposta. Acho que é um campo que, no meu entendimento, é obscuro ainda. (F6).

Podemos notar que a explicação que aproxima a fisiologia do corpo humano ao funcionamento de uma máquina, o corpo-máquina, seguindo o modelo de mecanismo enguiçado, não satisfez a F6. A explicação simplista do profissional pareceu ao familiar o não domínio do saber sobre uma questão que, para o segundo, mostra-se complexa.

$\mathrm{Na}$ tentativa de responder ao que é explícito na questão colocada pelos familiares, os profissionais se deparam com a complexidade do tema com o qual lidam.

\section{Loucura, doença mental e controle}

Os familiares, por sua vez, na entrada de um componente da família no circuito de tratamento e darem como sentido à loucura, à doença mental, que "não tem cura", passam a não acreditar nessa pessoa. O limite está na associação que correntemente se faz da pessoa com sofrimento psíquico com invalidez, com impossibilidade de sair desse lugar ${ }^{24}$. Dessa forma, não acreditam que o contato com a loucura possa ser de outra ordem, menos turbulento e menos sofrido, que possam encontrar meios de afirmar essa alteridade em suas possibilidades e modos relacionais. Como saída podem buscar a vigilância e o controle à pessoa com sofrimento psíquico, formas de lidar com a doença mental, apoiadas algumas vezes pelos profissionais de saúde que orientam os familiares neste sentido:

Eu não posso confiar nele. O sexo dele tá aqui [apontando a cabeça], ele é maníaco. Assim o Dr. X. me falou. Eu tenho que vigiar 24 horas. $O$ doutor X. falou: 'Dona $H$., a senhora tem que domar a fera porque se ele perceber que a senhora tem medo dele, a senhora tá perdida. Ele é o contrário, ele tem que ter medo da senhora'. Ele tem medo de mim, ele me respeita, tudo ele me pede (F9).

O tratamento aqui é muito bom. Depois que ele entrou aqui, o controle, o domínio dele eu tenho (F1).

$O$ cuidado primeiro é que tem que estar vigiando. Então é 24 horas vigiando ele (F5).

Vigiar, controlar, dominar, submeter a loucura, presente nos relatos acima, são práticas que se aproximam às práticas manicomiais. Talvez os motivos para essas práticas possam ser explicados de outras formas, diferentes dos motivos que legitimavam as práticas nos manicômios; por exemplo, como medida de proteção da própria pessoa com sofrimento psíquico, que está colocando em risco a própria vida. No entanto, essas práticas podem estar a serviço de defesa contra a dor e sofrimento que a loucura traz ao abalar o suposto equilíbrio da família e convidá-la a novos modos de existência.

De qualquer forma, o louco como doente mental é colocado como incapaz, irresponsável, perigoso, controlado e excluído em espaços fechados. Nesse caso, esse espaço é a própria família e a lógica manicomial é sustentada pelos 
familiares. Estar junto à família, para o louco, nem sempre é garantia de convívio social, de ver afirmado seu modo de ser e estar no mundo.

\section{CONSIDERAÇÕES FINAIS}

Neste trabalho foi destacado que, para os profissionais e familiares entrevistados, a loucura é reduzida à sua dimensão de doença. Despotencializados, tristes, voltados para os encargos, esses familiares em defesa contra a dor e o sofrimento que a loucura traz ao convidá-los a novos modos de existência, vigiam e controlam a pessoa com sofrimento psíquico, na esperança de alcançar a estabilidade na condução de suas vidas.

Isto ressalta a importância de ações junto aos familiares no sentido de que o cuidado da pessoa com

\section{REFERÊNCIAS}

1. Melman J. Família e doença mental: repensando a relação entre profissionais de saúde mental e familiares. São Paulo: Escritura; 2001.

2. Friche ICP, Da Fonseca MS. Concepções e práticas sociais em torno da loucura: alcance e atualidade da história da loucura de Foucault para investigações etnográficas. Psychê. 2003;7(12):137-58. Disponível em: http://www.redalyc.org/ articulo.oa? $\mathrm{id}=30701210$.

3. Brasil. Ministério da Saúde. Sistema único de Saúde. Conselho Nacional de Saúde. Relatório final da III Conferência Nacional de Saúde Mental. Brasília: Conselho Nacional de Saúde/Ministério da Saúde; 2002. Disponível em: http://conselho.saude.gov.br/biblioteca/relatorios/ saude mental.pdf.

4. Fiorin JL. Linguagem e ideologia. São Paulo: Ática; 2007.

5. Vechi LG. Iatrogenia e exclusão social: a loucura como objeto do discurso científico no Brasil. Est. Psicol. 2004;9(3):48995. http://dx.doi.org/10.1590/S1413-294X2004000300011.

6. Rotelli F, Leonardis O, Mauri D. Desinstitucionalização, uma outra via: a reforma psiquiátrica italiana no contexto da Europa Ocidental e dos "países avançados". In: Nicácio F, organizador. Desinstitucionalização. São Paulo: Hucitec; 2005. sofrimento psíquico seja construído junto, de forma compartilhada, com os serviços de assistência em saúde mental. Para chegar a isso, são vários os impasses enfrentados que partem da relação que profissionais e familiares mantém com a loucura.

Os profissionais entrevistados reduzem a complexidade da experiência da loucura à dimensão da falta, do prejuízo e suas manifestações são passíveis de serem classificadas, controladas, na tentativa de consertálas. Nega-se essa alteridade perdendo-se a oportunidade de produzir relações, encontros, coletividades, possibilidades múltiplas de existência.

O discurso da desinstitucionalização traz, em linhas gerais, o compromisso de buscar outras formas de relação com a loucura, que não a identifique com a falta. Nesse sentido, o desafio para quem lida com a loucura é buscar caminhos que valorizem sua dimensão existencial e humana.

7. Rolnik S. À sombra da cidadania: alteridade, homem da ética e reinvenção da democracia. In: Magalhães $\mathrm{MC}$, organizadores. Na sombra da cidade. São Paulo: Editora Escuta; 1997.

8. Morin E. Introdução ao pensamento complexo. Lisboa: Instituto Piaget Divisão Editorial; 2008.

9. Navarini V, Hirdes A. A família do portador de transtorno mental: identificando recursos adaptativos. Texto Contexto Enferm. 2008;17(4):680-7. Disponível em: http://www. scielo.br/pdf/tce/v17n4/08.pdf.

10. Koga M, Furegato AR. Convivência com a pessoa esquizofrênica: sobrecarga familiar. Rev Ciên Cuidado Saúde (Maringá). 2008;1(1):69-73. Disponível em: file://C:/ Users/Administrador/Downloads/5656-17308-1-PB\%20 (1).pdf.

11. Romagnoli RC. O sintoma da família: excesso de sofrimento e defesa. Interações. 2004;9(18):41-60. Disponível em: http://pepsic.bvsalud.org/scielo.php?pid=S141329072004000200003\&script=sci_arttext.

12. Romagnoli RC. Trabalhando com famílias na rede de saúde mental: dificuldades e desafios. Pulsional Rev Psicanal Clín Social. 2004;7(180):71-80.

13. Guattari F. Revolução molecular: pulsações políticas do desejo. São Paulo: Brasiliense; 1998. 
14. Colvero LA, Ide CA, Rolim MA. Família e doença mental: a difícil convivência com a diferença. Rev Esc Enferm USP. 2004;38(2):197-204. Disponível em: http://www.scielo.br/ pdf/reeusp/v38n2/11.pdf.

15. Moraski T, Hildebrandt L. As percepções de doença mental na ótica de familiares de pessoas psicóticas. Rev Eletrônica Enferm. 2005;7(2):195-206. Disponível em: http://www. revistas.ufg.br/index.php/fen/article/view/882/1056.

16. Maciel SC, Barros DR, Camino LF, Melo JRF. Representações sociais de familiares acerca da loucura e do hospital psiquiátrico. Temas Psicol (Ribeirão Preto). 2011;19(1):193204. Disponível em: http://pepsic.bvsalud.org/scielo. php?pid=S1413-389X2011000100015\&script=sci_arttext.

17. Gadamer H. O caráter oculto da saúde. Petrópolis: Vozes; 2006.

18. Andrade AN. Práticas psicológicas, epistemicídio e unidades básicas de saúde. Rev Psicol Política. 2007;7(13). Disponível em: http://www.fafich.ufmg.br/rpp/seer/ojs/viewarticle. php?id=18\&layout $=$ html.

19. Brasil. Ministério da Saúde. Secretaria-Executiva. Secretaria de Atenção à Saúde. Legislação em saúde mental: 19902004. 5a ed ampl. Brasília: Ministério da Saúde; 2004. Disponível em: http://bvsms.saude.gov.br/bvs/publicacoes/ legislacao_saude_mental_1990_2004_5ed.pdf.

20. Amarante P. A clínica e a reforma psiquiátrica In: Amarante P, organizador. Archivos de saúde mental e atenção psicossocial. Rio de Janeiro: Nau Editora; 2003.

21. Machado LD, Lavrador MCC. Por uma clínica de expansão da vida. Interface Comunic Saúde Educ. 2009;13(1.1):51521. Disponível em: http://www.scielo.br/pdf/icse/v13s1/ a04v13s1.pdf.

22. Minayo MCS. O desafio do conhecimento: pesquisa qualitativa em saúde. São Paulo: Hucitec; 2007.

23. Turato ER. Tratado da metodologia da pesquisa clínicoqualitativa. Petrópolis: Vozes; 2008.

24. Sousa Severo AK, Dimenstein M. O diagnóstico psiquiátrico e a produção de vida em serviços de saúde mental. Estudos Psicologia. 2009;14(1):59-67. Disponível em: http://www. scielo.br/pdf/epsic/v14n1/a08v14n1.

Artigo recebido em: 04.07.15

Artigo aceito em: 25.08.15 